\title{
Raman spectra of the Markovka chondrite (H4)
}

\author{
Sergey Voropaev ${ }^{(1)}$, Ute Böttger ${ }^{(2)}$, Sergey G. Pavlov ${ }^{(2)}$, Franziska Hanke ${ }^{(2)}$ Dmitri Petukhov $^{(3)}$
}

(1) GEOKHI RAS, Kosygina str. 19, Moscow, 119991 Russia.

(2) Institute of Optical Sensor Systems, German Aerospace Center (DLR), Rutherfordstraße 2, 12489

Berlin, Germany.

(3) Analytical Centre, Moscow State University, Leninskie Gory 1, Moscow, 119334 Russia.

\begin{abstract}
Raman spectroscopy and scanning electron microscopy methods were used to study the fragment of the Markovka' (H4 chondrite) meteorite. A characteristic set of silicate minerals (olivine, pyroxene), oxides and hydroxides (maghemite, goethite), troilite and carbonates (aragonite) was determined. The structural features revealed by Raman spectroscopy allow us to draw important conclusions on thermal history of the parent body including both the temperature experienced by the rock on the parent body and their cooling rate as well as the constraints on the size of the parent body and the Mg-composition of the assumed fluid.
\end{abstract}

Keywords: meteorite, chondrite, thermal history, asteroid, carbonates

\section{Introduction}

Chondrite meteorites, which are generally accepted to be accreted from very pristine materials of the solar system, are grouped into three petrologic classes: carbonaceous, ordinary and enstatite chondrites. On the basis of their iron and other metal contents, the ordinary chondrites are further subdivided into three chemical classes: H, L and LL, and types 3, 4, 5 and 6, depending on the intensity of thermal metamorphism: type 3 is unheated, while types 4 through 6 have been progressively heated ${ }^{[1,2]}$. It was shown that Raman spectroscopy can provide valuable information about mineral composition and thermal history of ordinary and carbonaceous chondrites ${ }^{[3-7]}$. Freshly fallen meteorites are particularly valuable for the planetary science community because they typically contain very old ( 4.55 billion years old) material from the early solar nebula that has not been altered by terrestrial weathering. Thus, they can provide scientists with a wealth of new data that yield insights into early solar system processes. The stone rain' fall of the Markovka (H4) chondrite, 1967 East Siberia, Russia, provides an interesting sample for detailed investigation of its content, alteration and origin of the parent asteroid.

Geochemical data on oxygen ${ }^{16} \mathrm{O} /{ }^{17} \mathrm{O} /{ }^{18} \mathrm{O}$ isotope ratios supposed a close relationship of H3-H6 chondrites in contrast to L and LL types ${ }^{[8]}$. To explain this phenomenon a number of thermochronometric and geochronological methods were involved, including retention of fission tracks and $\mathrm{Pb}-\mathrm{Pb}$ ages ${ }^{[9]}$, metallographic cooling rates derived from $\mathrm{Ni}$ zoning in $\mathrm{Fe}-\mathrm{Ni}$ alloys ${ }^{[10]}$, opxcpx and others thermobarometers ${ }^{[11]}$. These studies of the thermal evolution of H-chondrites were based on determination of two main parameters: (1) the distribution of metamorphic peak and closure temperatures for the various petrologic types, as inferred from mineralogy, and (2) cooling rates. The correlation between these parameters is not obvious, mainly due to disagreement between estimated 
values of the various cooling rates. A simple "onion-shell"model ${ }^{[12]}$ for internally heated (i.e., due to radioactive decay of ${ }^{26} \mathrm{Al} \rightarrow{ }^{26} \mathrm{Mg}+\beta$ ) chondrite parent bodies should produce an inverse correlation, that is, slow cooling in the deep interior for higher petrologic types H5-H6, and more rapid cooling near the periphery for lower petrologic types H3-H4. However, it was noted that for some cases there appears to be no correlation between the metallographic data, two-pyroxene thermometry and petrologic type. Therefore, a "metamorphosed-planetesimal" model was developed to resolve this discrepancy. In this model, heating occurs in small objects that are subsequently randomly accreted into larger parent bodies ${ }^{[13]}$.

It is worth noting that the rheology of asteroids differs from planets - these are rigid pieces of rock compressed by their own gravity. To date, important updates were obtained on the topography and the gravity of asteroids as from the asteroids belt (Vesta, Ceres) and as of the near-Earth' families (Eros, Ryugu). These data show asteroids as coherent, but heavily fractured objects with the mean density of between $2 \mathrm{~g} / \mathrm{cm}^{3}$ and $3 \mathrm{~g} / \mathrm{cm}^{3}$ indicating on a stony composition, like chondrites, with significant porosity. Thus, the well-understood theory of gravitational potential can be used to calculate elastic deformations and stresses $\left(\sigma_{\mathrm{ij}}\right)$ of a small spherical body with a radius $\mathrm{R}^{[14]}$ :

$\partial \sigma_{\mathrm{rr}} / \partial \mathrm{r}+2\left(\sigma_{\mathrm{rr}}-\sigma_{\theta \theta}\right) / \mathrm{r}=-\rho \cdot \mathrm{g} \cdot \mathrm{r} / \mathrm{R}, \quad \sigma_{\theta \theta}=\sigma_{\varphi \varphi}$,

where $\mathrm{r}$ is the radial distance from the bodies centre at the spherical reference system $(r, \theta, \varphi), \rho$ is the bodies mean density, $g=4 / 3 \pi \cdot \rho \cdot G \cdot R$ - is the gravity acceleration on the surface, $G$ is the gravity constant. Spherically symmetric solution of (1) for the components of the stress tensor, $\sigma_{\text {rr }}(r)$ and $\sigma_{\theta \theta}(\mathrm{r})$, provides total pressure at bodies centre at $\mathrm{r}=0$ as

$\sigma(0)=\sigma_{\mathrm{rr}}(0)+\sigma_{\theta \theta}(0)+\sigma_{\varphi \varphi}(0)=3 / 10 \cdot \rho \cdot g \cdot R \cdot(3-v) /(1-v)$

where $v-$ is the Poisson' elasticity coefficient with the mean value of between 0.15 and 0.25 for chondrites ${ }^{[15]}$.

Knowing the pressure and temperature margins in the interior of the parent body of the asteroid will allow us to constrain the possible phase transitions and the presence of polymorph minerals. In this paper, we analyze a composition of the Markovka (H4) chondrite by Raman micro-spectroscopy, a nondestructive analytical technique, providing complementary, spatially-resolved data to chemical analysis. We show what kind of information concerning parent asteroids genesis and evolution can be derived by Raman spectroscopy.

\section{Methods}

\section{Sample preparation and characterization.}

The small fragment of the Markovka chondrite (H4) with dimensions about $3 \times 2 \times 2 \mathrm{~cm}^{3}$ (see Fig.1), used in this work, is a part of the large meteorite fall in 1967 near Markovka village, east Siberia, Russia. The fall was a stone rain with fragmented chondrite bodies, with the typical sizes up to $1 \mathrm{~m}$, which was collected and is currently stored in the meteorite collection of the Russian Academy of Sciences. (See for details official reference at Meteoritic Bulletin ${ }^{[16]}$ ) 


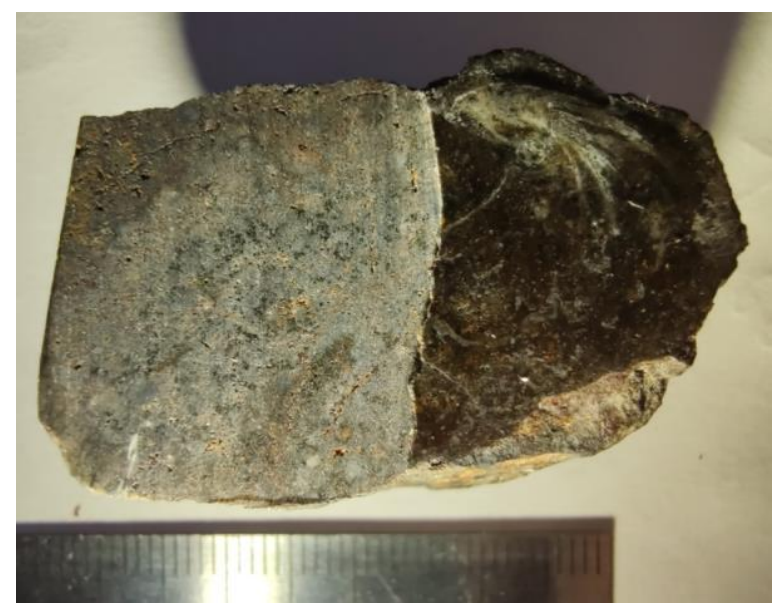

Fig. 1. Markovka' (H4) chondrite fragment

A fresh cutted plate with the size ca. $1 \times 1 \mathrm{~cm}^{2}$ was used for the investigations.

SEM-EDX. Chemical composition of the samples was determined by a combination of scanning electron microscopy (SEM) and energy dispersive X-Ray microanalyses (EDX). Leo Supra 50VP microscope equipped with Oxford-Instruments X-Max detector from Analytical Centre, Moscow State University, was used. Measurement parameters of the microscope system during analysis were: low pressure (40 Pa) $\mathrm{N}_{2}$ atmosphere, $15 \mathrm{kV}$ electron beam with a working distance of $7 \mathrm{~nm}$, VPSE (Microscopy Variable, Pressure Secondary Electron) detector, and magnifications from 200x to 2500x. The X-Ray microanalysis was done by taking the EDX spectra from the selected areas and by mapping of the sample area. Identification and quantification of the elements were done after ZAF-correction (the corrections of the X-ray intensities against those from a standard specimen in order to eliminate changes caused by the atomic-number $\mathrm{Z}$, the absorption $\mathrm{A}$ and the fluorescence excitation F). Maps of the main elements allowed us to identify minerals/metal alloys and simplifies subsequent spectroscopic analysis (see Fig.2).
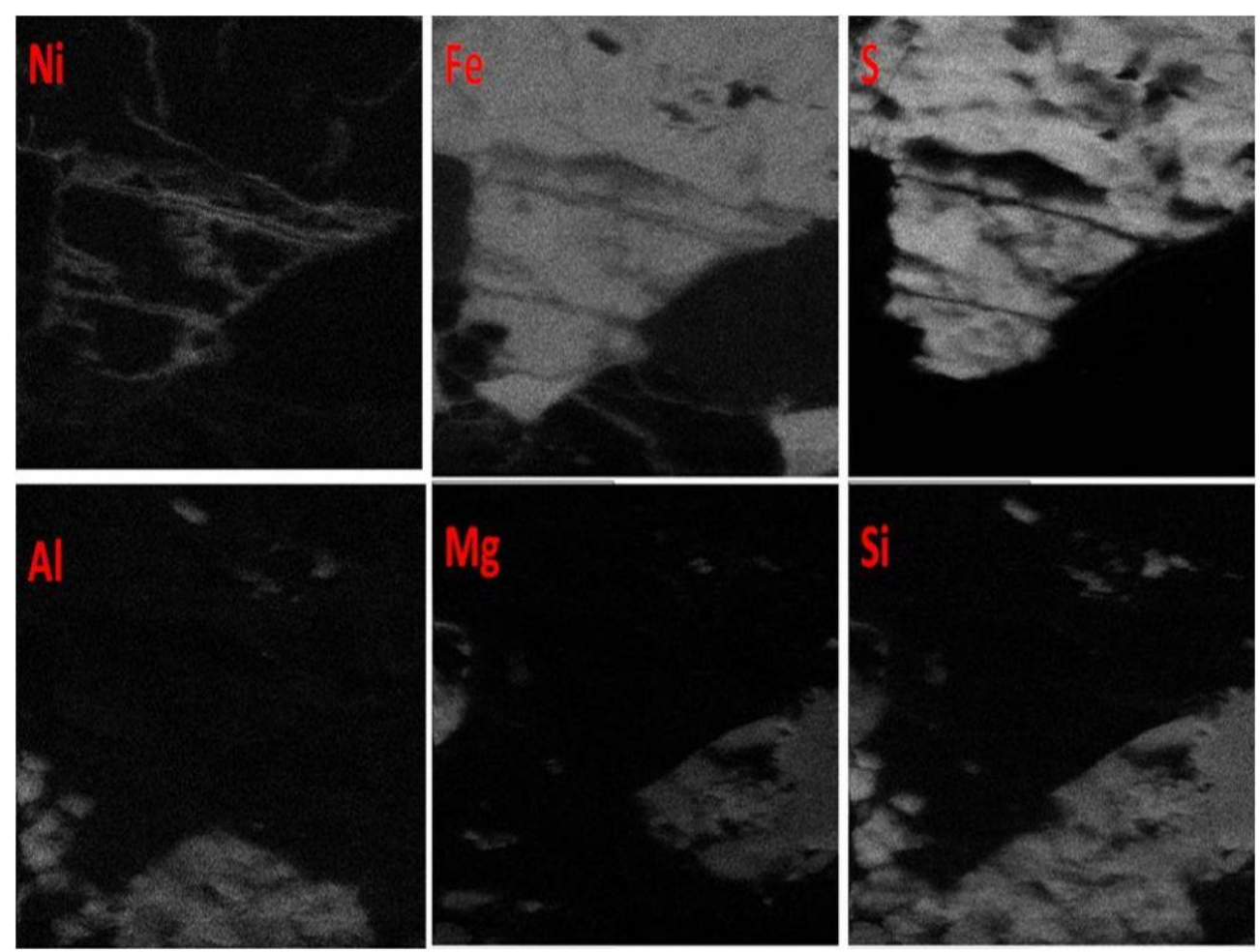
Fig.2. Examples of SEM-EDX maps with $\mathrm{Ni}, \mathrm{Fe}, \mathrm{S}, \mathrm{Al}, \mathrm{Mg}, \mathrm{Si}$ for troilite $\mathrm{Fe}(\mathrm{Ni}) \mathrm{S}$ (top row) and for plagioclase $\mathrm{Na}(\mathrm{Ca}) \mathrm{AlSi}_{2} \mathrm{O}_{8}$ (down row)

Quantitative chemical data are possible with accuracy till of wt. $0.01 \%$. Typical values for the main groups of minerals are presented in Table 1.

Table 1. Chemical composition of main minerals' groups in the Markovka' meteorite, as from SEMEDX analysis.

\begin{tabular}{|l|l|l|l|l|l|l|l|l|l|}
\hline Mineral group & \multicolumn{6}{|l|}{ Composition, $\mathrm{wt} \%$} \\
\hline & $\mathrm{MgO}$ & $\mathrm{Al}_{2} \mathrm{O}_{3}$ & $\mathrm{SiO}_{2}$ & $\mathrm{Na}_{2} \mathrm{O}$ & $\mathrm{P}_{2} \mathrm{O}_{5}$ & $\mathrm{CaO}$ & $\mathrm{K}_{2} \mathrm{O}$ & $\mathrm{FeO}$ & $\begin{array}{l}\text { \#Mg-\#Fe-\#Ca } \\
\text { X*100/(Mg+Fe+Ca })\end{array}$ \\
\hline & 42.51 & 0.03 & 39.86 & 0 & 0 & 0.03 & 0 & 18.15 & $80-20-0$ \\
\hline Olivine & 42.58 & 0.04 & 39.77 & 0.06 & 0.34 & 0.02 & 0 & 18.01 & $80-20-0$ \\
\hline Pyroxene & 30.59 & 0.17 & 57.13 & 0.02 & 0.35 & 0.85 & 0.01 & 11.84 & $82-16-2$ \\
\hline Plagioclase & 30.92 & 0.15 & 57.37 & 0.02 & 0.35 & 0.72 & 0.01 & 11.41 & $81-17-2$ \\
\hline & 0.09 & 22.32 & 67.84 & 10.34 & 0 & 2.51 & 0.98 & 0.69 & $\mathrm{An}_{12} \mathrm{Ab}_{84} \mathrm{Or}_{4}$ \\
\hline
\end{tabular}

Silicates (olivine, pyroxene), plagioclase (albitic low-Ca composition), Fe-hydroxides, FeS (troilite) and FeNi alloys were recognized.

\section{Raman spectroscopy}

Raman spectra of the Markovka' meteorite were collected at the Raman laboratory of the Institute of Planetary Research at DLR Berlin using a Witec Alpha 300 System Raman microscope-spectrometer equipped with a 532nm Nd:YAG laser and a 10x objective for Raman scattered light acquisition (see for details $\left.{ }^{[7]}\right)$.

In order to avoid a heat-related alteration of sensitive iron-containing mineral phases, Raman spectra were taken at reduced laser powers and in vacuum $\left(\sim 10^{-5} \mathrm{mbar}\right)$. For this, the Markovka' sample was mounted inside a vacuum chamber placed on a 2D movable scanning table under the Raman microscope. The spectra were recorded at room temperature in backscattering geometry in the Stokes shifted range from 100 to $3200 \mathrm{rel} . \mathrm{cm}^{-1}$ with a spectral resolution of approximately $4 \mathrm{~cm}^{-1}$. The power of the laser was varied in the range of $0.3-3 \mathrm{~mW}$ with a focal spot on the sample of about $1.5 \mu \mathrm{m}$. We started from the lower power at each new location first, in order to avoid potential thermal effects. As far as mineral phases were recognized, the laser power was increased step-by-step and spectra were taken at $1 \mathrm{~mW}$ and $3 \mathrm{~mW}$, for comparison. The spectrometer was wavelength-calibrated using a neon lamp, and the Stokes shifts were linked to the optical phonon in a silicon sample $\left(521 \mathrm{~cm}^{-1}\right)$. Peak positions of the Raman lines were found by the least squares regression method using the Witec evaluation software.

Raman spectra of minerals can be affected by the impurities imposed by the thermal diffusion and geochemical substitution of elements. The reference spectra of several standard mineral classes, such as olivine, pyroxene, plagioclase were collected for direct comparison and stored in databases. 


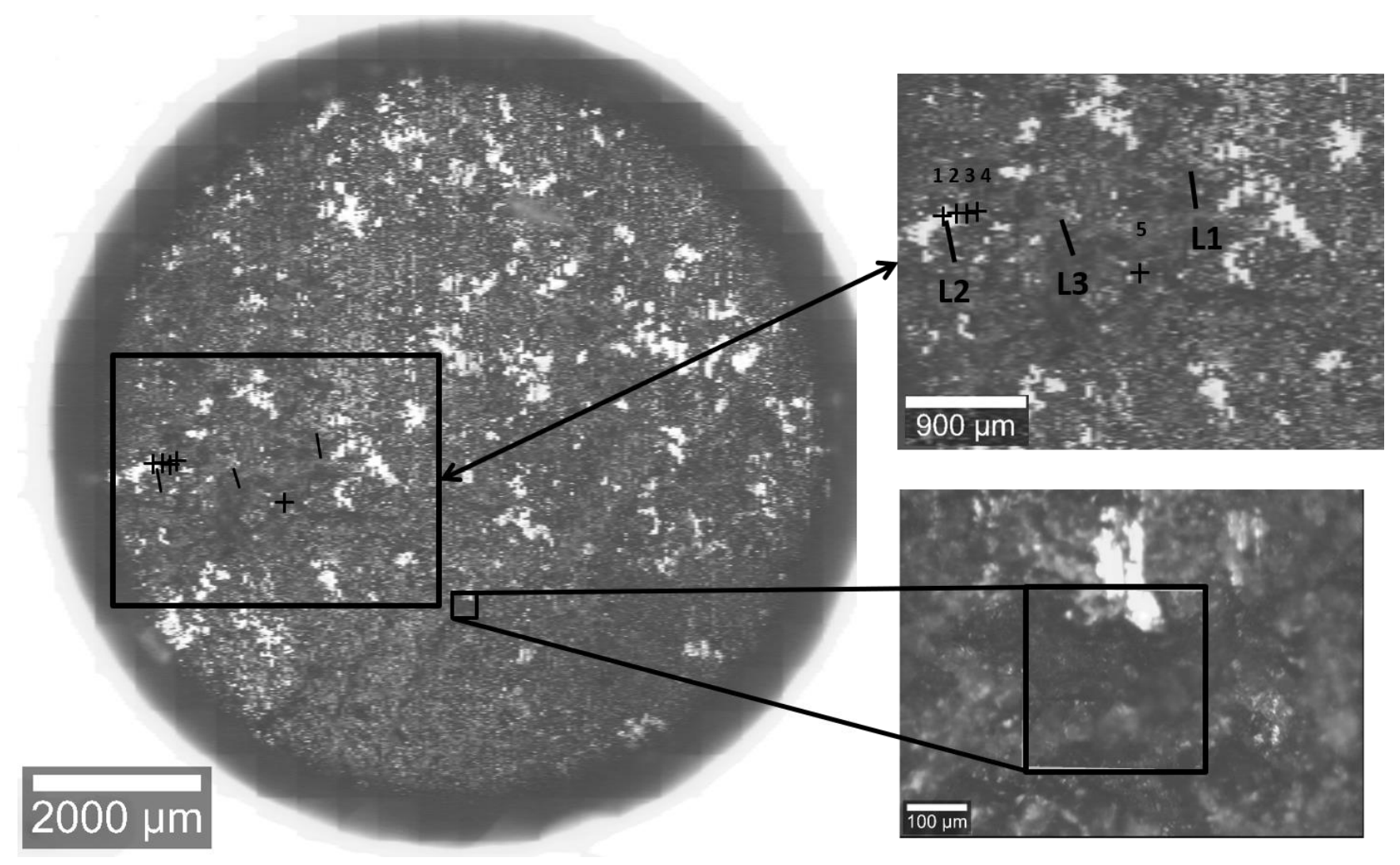

Fig. 3. General view of the investigated regions on the Markovka' meteorite sample. Left: image of $\varnothing 9 \mathrm{~mm}$ area taken through the optical path of the Raman microscope. Right upper plots: enlargements of the investigated areas with the positions of single point measurements, line (L) scans. Right lower microscopic image: enlargements of the investigated areas with area scans.

The choice of the sampling areas was made by intuitive search for the places with various optical contrast as well as at several randomly selected positions. In all these places, test spectra were taken and served to a final decision of the point-to-point measurements, linear and area scans (Fig 3). Area scans were made in vicinity of detected characteristic phases, to show the phase' distribution maps. Linear scans were taken to accurately show the areas crossing several phases in order to further separation and verification of the strongly mixed phase cases. Point measurements were made where a sole phase or a few phase mixture were found by the rapid test search.

Three linear scans of $275 \mu \mathrm{m}, 295 \mu \mathrm{m}$ and $280 \mu \mathrm{m}$ total length, respectively, with 50 steps per scan, and according step size of around $6 \mu \mathrm{m}$ were performed to cross a couple of characteristic areas. The area scan comprises an area of $300 \mu \mathrm{m} \times 300 \mu \mathrm{m}$ with $75 \times 75$ measurement points with a step size of $4 \mu \mathrm{m}$. The measurement time was $10 \mathrm{~s}$ integration time per point. This allowed fast determination of major mineral phases in the sample: silicates (olivine, pyroxene), plagioclase and iron oxide.

\section{Results and Discussion}

Spectra at different locations on the meteorite are commonly (at a very few exceptions) from a few phases (Fig 4). Admixing of mineral phases results in the broadening of characteristic vibration bands and common lowering of magnitudes, known for highly inhomogeneous samples such as meteorites.

Three "optically" different regions (indicated as L1, L2 and L3 in Fig. 3) were selected. The mineral phases found in the Markovka' meteorite fragment by Raman spectroscopy are presented in the Fig. 4. 

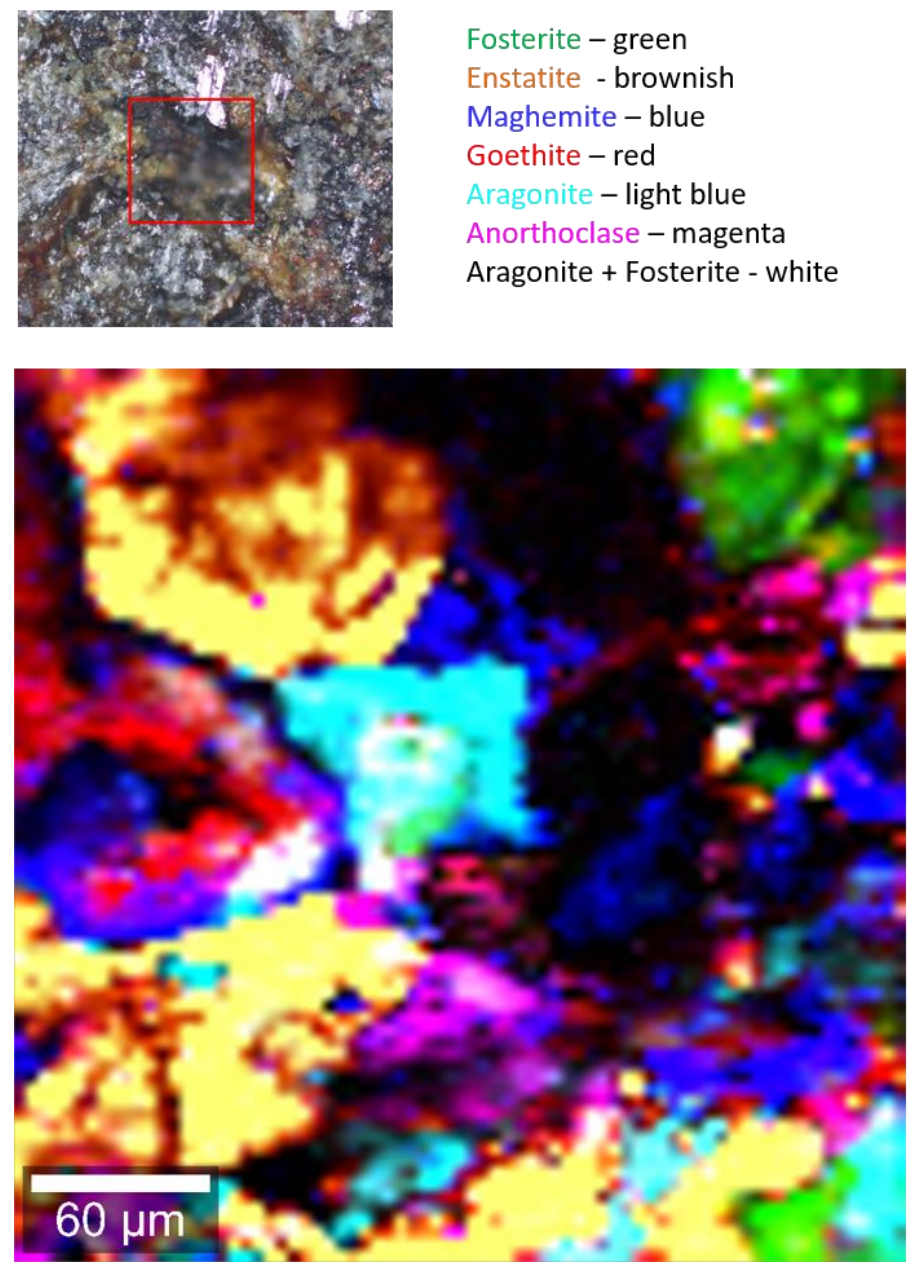

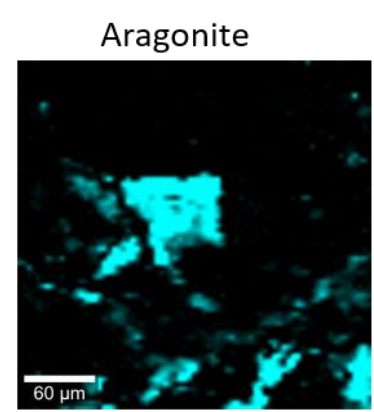

Enstatite

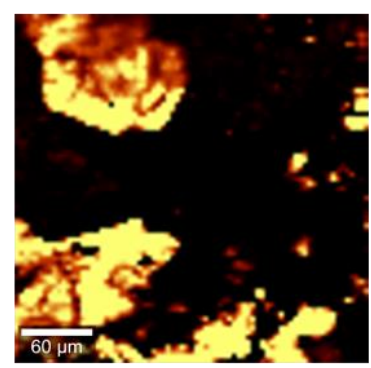

Anorthoclase

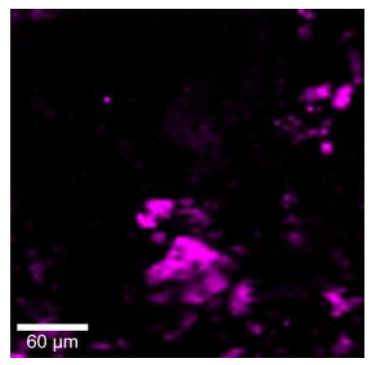

Fosterite

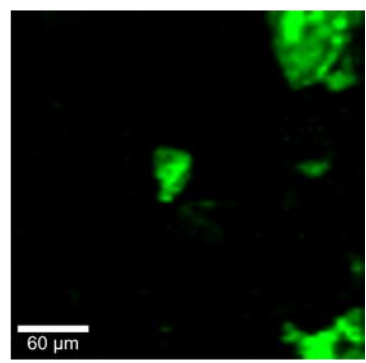

Goethite

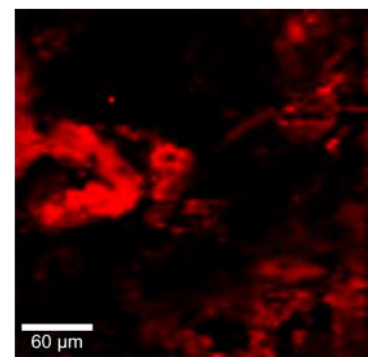

Maghemite

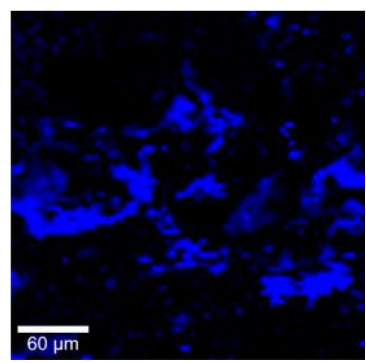

Fig. 4. Maps of the mineral phases in the Markovka' meteorite confirmed by Raman spectroscopy, upper left: image of the selected area taken by the optical Olympus microscope. Lower left Color composite of mineral phases in the selected area; right - color coded maps of individual mineral phases.

\section{Silicates.}

Silicates is the most abundant mineral phase and spread over entire area in the meteorite (see Fig. 4). They are presented mainly by orthosilicates $\left(\left[\mathrm{SiO}_{4}\right]^{4-}\right)$ olivine and inosilicates $\left(\left[\mathrm{Si}_{n} \mathrm{O}_{3 n}\right]^{2 n-}\right.$ ) pyroxene groups.

The olivine spectra are dominated by the $\mathrm{SiO}_{4}$ tetrahedra internal stretching $\left(v_{1}, v_{3}: 820-960 \mathrm{~cm}^{-1}\right)$ and bending $\left(v_{2}, v_{4}: 400-610 \mathrm{~cm}^{-1}\right)$ modes, with most strong transitions for the stretching modes, used for general classification of olivines. The stretching modes $v_{\mathrm{AS}}\left(\mathrm{Si}-\mathrm{O}\right.$ asymmetric stretching, $\left(v_{1}+v_{3}\right)_{\mathrm{AS}}$ and $v_{S S}\left(\right.$ Si-O symmetric stretching $\left(v_{1}+v_{3}\right)$ SS exhibit a constant energy difference $v_{A S}-v_{S S}=32 \mathrm{~cm}^{-1}$ in the recorded spectra presenting olivines. The modes peak at $v_{\mathrm{AS}}=854 \mathrm{~cm}^{-1}$ and $v_{\mathrm{SS}}=822 \mathrm{~cm}^{-1}$, that classifies the observed olivines to an average composition of $\mathrm{Fa}_{20} \mathrm{Fo}_{80}$ : Fo values $(\mathrm{Fo}=\mathrm{Mg} /(\mathrm{Mg}+\mathrm{Fe})$ in a mole; were obtained using the calibration ${ }^{[17]}$; which is in a very good relation to the SEM-EDX data (Table 1). Both mentioned values indicate on a Mn-poor forsterite, otherwise increasing the intermode energy spacing ${ }^{[18]}$. The same arguments exclude significant abundances of Co-olivine and Ni-olivine in the investigated areas on a meteorite. Detailed SEM-EDX analysis of Markovka' olivine provides following composition (in wt \%)-: $\mathrm{Mn}-0.03, \mathrm{Co}-0.012, \mathrm{Ni}-0.012$. 
With the accuracy of used spectral resolution, we cannot be confident on the partial occurrence of $\mathrm{Ca}$ in the M2 site of olivines that could be potentially linked to a minor blue shift (not exceeding $4 \mathrm{~cm}^{-1}$ ) of the $\mathrm{SiO}_{4}$ stretching modes. This assumption however cannot be unambiguously confirmed by the low-energy part of the olivine spectra at different locations (Fig. 5), where the lines are rather pureolivine or mixed with other phases. For instance, the line at $214 \mathrm{~cm}^{-1}$ (Point 4, Fig. 4) can be assigned both to a $\mathrm{T}\left(\mathrm{SiO}_{4}\right)$ translation $\mathrm{Ag}_{\mathrm{g}}$ mode of forsterite $\left(\mathrm{Mg}_{80}, \mathrm{Fe}_{20}\right)_{2} \mathrm{SO}_{4}$ and to a $\mathrm{T}\left(\mathrm{SiO}_{4}\right) \mathrm{B}_{3 \mathrm{~g}}$ mode of monticellite $\left(\mathrm{CaMgSiO}_{4}\right)^{[19]}$.

We note that alone olivine component (within the scale of the diagnostic laser spot, $1.5 \mu \mathrm{m}$ ) was found only at a few exclusive locations (e.g. Point 4 in Fig. 5). In this case we could safely increase the excitation intensity in order to resolve weaker lines in the low-energy part of the spectrum. Beside the internal $\mathrm{SiO}_{4}$ modes, only the characteristic for a $\mathrm{Si}-\mathrm{O}$ bond, vibration modes were observed in this case: a $\mathrm{T}\left(\mathrm{SiO}_{4}\right)$ translation mode and a mixed $\mathrm{M} 2+\mathrm{R}\left(\mathrm{SiO}_{4}\right)$ translation + libration mode at $222 \mathrm{~cm}^{-1}$ and $314 \mathrm{~cm}^{-1}$ respectively (mode assignment as from ${ }^{[19]}$ ). No characteristic cation (M)-related vibration modes, such as M-oxygen bond modes at below $500 \mathrm{~cm}^{-1}$ were resolved in the strongly overlapped spectra and cannot be used for justification of possible occurrence of low Ca or trace transition metals in the olivine molecule sites.

Mixed spectra of a few mineral phases were often presented in the Raman spectra (Points 2, 3 in Fig. 5). Two specific bands lying between $450 \mathrm{~cm}^{-1}$ and $515 \mathrm{~cm}^{-1}$ in the Raman spectrum at Position 2 (Fig. 5) indicate on admixed tectosilicates with typical ring-breathing $\mathrm{RB}\left(\mathrm{SiO}_{4}\right)$ modes of the fourmembered rings of tetrahedra, while the strongest band peaked at $510 \mathrm{~cm}^{-1}$ is typical for feldspar group with a four-membered ring ${ }^{[20]}$. The characteristic set of $\mathrm{RB}\left(\mathrm{SiO}_{4}\right)$ modes: (weak $455 \mathrm{~cm}^{-1}, 480 \mathrm{~cm}^{-1}$, $\left.510 \mathrm{~cm}^{-1}\right)$ constrains the classification of this feldspar to high-temperature plagioclase group ( $(\mathrm{Ca}$, $\left.\mathrm{Na})(\mathrm{Al}, \mathrm{Si})_{4} \mathrm{O}_{8}\right)$ while the lowest-energy cage-shear band $\left(150-200 \mathrm{~cm}^{-1}\right)$ has a peak at about $169 \mathrm{~cm}^{-1}$, right between the values for oligoclase $\left(161 \mathrm{~cm}^{-1}, \mathrm{Na} /(\mathrm{Ca}+\mathrm{Na})\right.$ ranges from $70 \%$ to $\left.90 \%\right)$ and andesine $\left(177 \mathrm{~cm}^{-1}, \mathrm{Ca} /(\mathrm{Ca}+\mathrm{Na}) \text { is between } 30-50 \%\right)^{[20]}$.

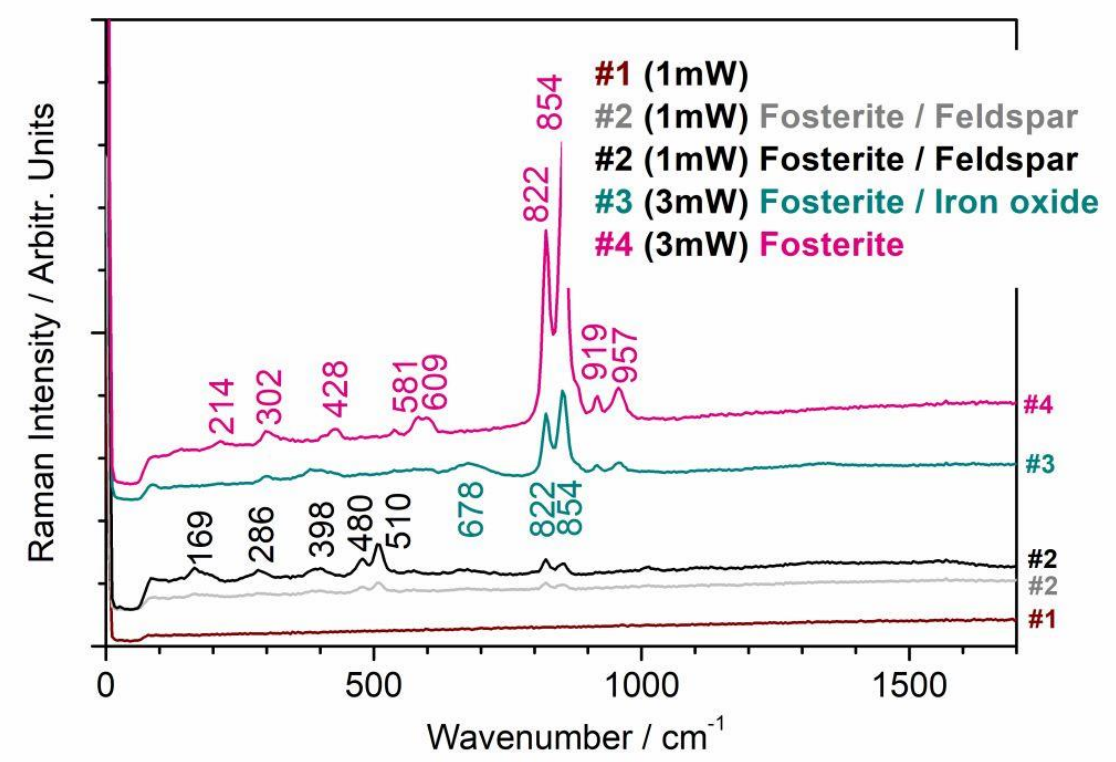

Fig. 5. Raman spectra of the Markovka meteorite at different locations \#1 - 4 with commom olivine abundance (characteristic lines at $>822 \mathrm{~cm}^{-1}$ ). The laser power at positions \#1 and \#2 was $\sim 1 \mathrm{~mW}$, 
and at positions \#3 and \#4 3 $\mathrm{mW}$. Spectra at positions \#2 are identic and differ only in intensities of the observed bands. Spectra are shifted vertically for the better viewing.

Next abundant silicate phase, found in the investigated sample, is pyroxene (Fig. 6 top). Structurally, pyroxene is presented as individual grains and cement between grains of olivine. In the grains, the Raman spectra exhibit a range of characteristic Mg-Fe orthopyroxene (opx) series - enstatite (En: $\mathrm{MgSiO}_{3}$ ) - ferrosilite $\left(\mathrm{Fs}: \mathrm{FeSiO}_{3}\right)$. It is known that for the opx series at H-chondrites the characteristic Raman spectral regions are $850-1050 \mathrm{~cm}^{-1}\left(v\left(\mathrm{Si}-\mathrm{O}_{\mathrm{nb}}\right)\right.$ stretching modes), 630-750 ( $v\left(\mathrm{Si}-\mathrm{O}_{\mathrm{b}}-\mathrm{Si}\right)$ bending modes) and weaker $v(\mathrm{O}-\mathrm{Si}-\mathrm{O})$ bend bands at 500-600 $\mathrm{cm}^{-1}$, where $\mathrm{O}_{\mathrm{nb}}$ and $\mathrm{O}_{\mathrm{b}}$ stand for nonbonded oxygen and the chain-bonded oxygen of the $\mathrm{SiO}_{4}$ tetrahedron of inosilicates, respectively ${ }^{\text {[21] }}$. The low-energy broad bands can be attributed to lattice vibration modes: a metal(M)-O stretch to those with peaks at about $233 \mathrm{~cm}^{-1}, 336 \mathrm{~cm}^{-1}$ and a Mg-O stretch to those with a peak at about $396 \mathrm{~cm}^{-1}$. The lines set of $1009 \mathrm{~cm}^{-1} ; 662 \mathrm{~cm}^{-1} / 683 \mathrm{~cm}^{-1}$ and $336 \mathrm{~cm}^{-1}$ of the Markovka' sample (enstatite, Fig. 6 top) allows to constrain a low-Ca composition of $\mathrm{En}_{82} \mathrm{Fs}_{16} \mathrm{Wo}_{2}$, using calibrations of these lines from ${ }^{\text {[21] }}$. This fits well to the SEM-EDX data. Virtually constant Fo and Fs contents in both low-Ca pyroxene and olivine indicate the equilibrated grains experienced medium thermal metamorphism. Thus, $\mathrm{Mg}, \mathrm{Fe}$ and Ca partitioning between minerals has progressed almost to completion.

Iron Oxides and Oxyhydroxides. Spectral features of maghemite $\left(\gamma-\mathrm{Fe}_{2} \mathrm{O}_{3}\right)$ (Fig. 6 middle) have been found in several scans. Magnetite $\left(\mathrm{Fe}_{3} \mathrm{O}_{4}\right)$ is known to undergo the following phase transitions with temperature increase ${ }^{[22]}$

$\mathrm{Fe}_{3} \mathrm{O}_{4} \rightarrow \gamma-\mathrm{Fe}_{2} \mathrm{O}_{3}\left(200{ }^{\circ} \mathrm{C}\right) \rightarrow \alpha-\mathrm{Fe}_{2} \mathrm{O}_{3}\left(400{ }^{\circ} \mathrm{C}\right)$,

where maghemite $\left(\gamma-\mathrm{Fe}_{2} \mathrm{O}_{3}\right)$ is transformed to hematite $\left(\alpha-\mathrm{Fe}_{2} \mathrm{O}_{3}\right)$ starting at about $400{ }^{\circ} \mathrm{C}$. Since any evidence of hematite was found in the Raman spectra of the samples (see Fig. 6 top) we suppose that the maximum temperature of the Markovka' parent body did not exceed $400{ }^{\circ} \mathrm{C}$. It provides important physical constraint on the model of its evolution.

Despite small differences in the Stokes line peak positions (within $\pm 5 \mathrm{~cm}^{-1}$ ), there is good agreement in the reported spectra of goethite $(\alpha-\mathrm{FeOOH})$ with the observed broad spectral bands centered at about $299 \mathrm{~cm}^{-1}, 395 \mathrm{~cm}^{-1}, 479 \mathrm{~cm}^{-1}, 550 \mathrm{~cm}^{-1}$ and $685 \mathrm{~cm}^{-1}{ }^{[23]}$ (see Fig. 6 bottom). The Raman spectrum of lepidocrocite $(\gamma-\mathrm{FeOOH})$ has also been extensively investigated and there is a consensus on the most important peaks of $245 \mathrm{~cm}^{-1}, 373 \mathrm{~cm}^{-1}, 493 \mathrm{~cm}^{-1}$ (shoulder), $522 \mathrm{~cm}^{-1}$ and 650 (shoulder) $\mathrm{cm}^{-1}[24]$. 


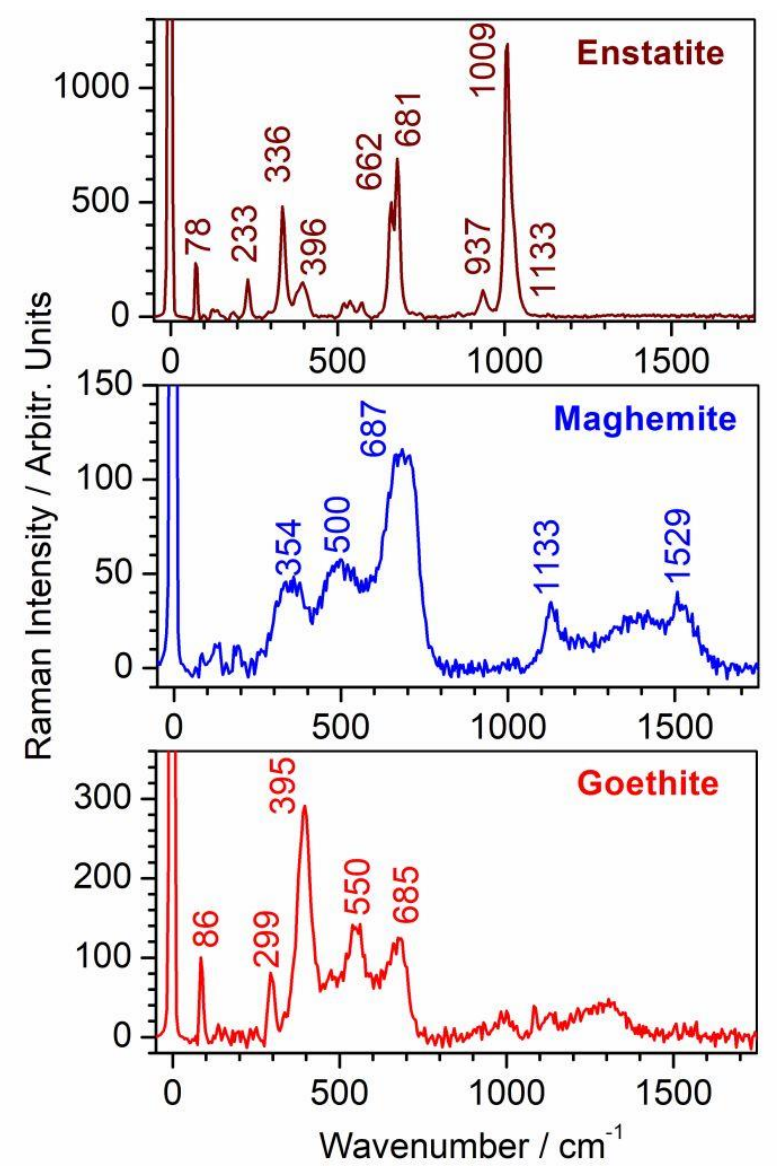

Fig. 6. Typical pyroxene (top graph) and iron oxides in the Raman spectra of the Markovka' sample.

Lepidocrocite is formed in the weathering crusts of basic and ultramafic rocks, oxidation zones (iron hats) as a result of hydrolysis of Fe-containing minerals during a hydrothermal low-temperature process. These lines were not detected in the Markovka' sample and it is an indication of weak ground contamination.

Aragonite. Most remarkable in the Markovka' (H4) meteorite is the finding of carbonates - namely, aragonite $\left(\mathrm{CaCO}_{3}\right)$ (Fig. 7). Carbonate minerals are typical for the $\mathrm{CM}$ group carbonaceous chondrite meteorites, along with silicates and sulphides, with which they are intergrown ${ }^{[25]}$. Widely accepted, $\mathrm{CM}$ carbonaceous chondrites were altered from their original anhydrous mineralogy by aqueous fluids shortly after parent body accretion. But, H-chondrites are dry and have low carbon content, usually. 


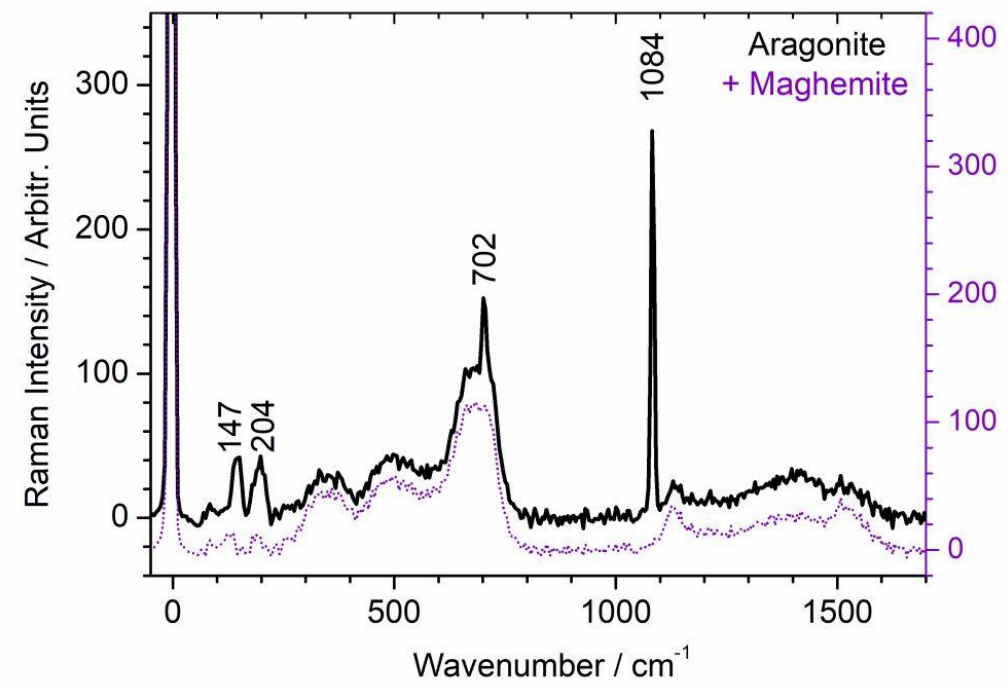

Fig. 7. Discrete line of aragonite in the Raman spectra of the Markovka' sample, occurred with admixed maghemite. The maghemite spectrum, characterized with broad Raman bands, is shown in the background for a comparison.

Two well-known carbonate polymorphs, calcite (trigonal structure, R-3c) and aragonite (orthorhombic structure, Pmcn), have similar lines in the spectrum caused by the symmetric $\mathrm{CO}_{3}$ stretching mode $\left(1086 \mathrm{~cm}^{-1}\right.$ and $1084 \mathrm{~cm}^{-1}$, respectively). A significant difference is noticeable for the low-frequency oscillation modes that are more sensitive to structural changes: $282 \mathrm{~cm}^{-1}$ for calcite and $204 \mathrm{~cm}^{-1}$ for aragonite ${ }^{[26]}$. The vibrational bending modes also differ: the doublet characteristic of aragonite at 702 $\mathrm{cm}^{-1}$ is visible in the Raman spectrum of the Markovka (see Figure 7).

For the Earth geology, aragonite is usually indicative for the blueschist metamorphic conditions for which the range in the peak temperature is $\sim 200-350{ }^{\circ} \mathrm{C}$ and the pressure is $\sim 700 \mathrm{MPa}{ }^{[27]}$. Using the overall transformation rate of aragonite to calcite, the partial transformation of aragonite to calcite was explored to constrain P-T-t paths for rocks metamorphosed at convergent plate junction (see Fig. 8)

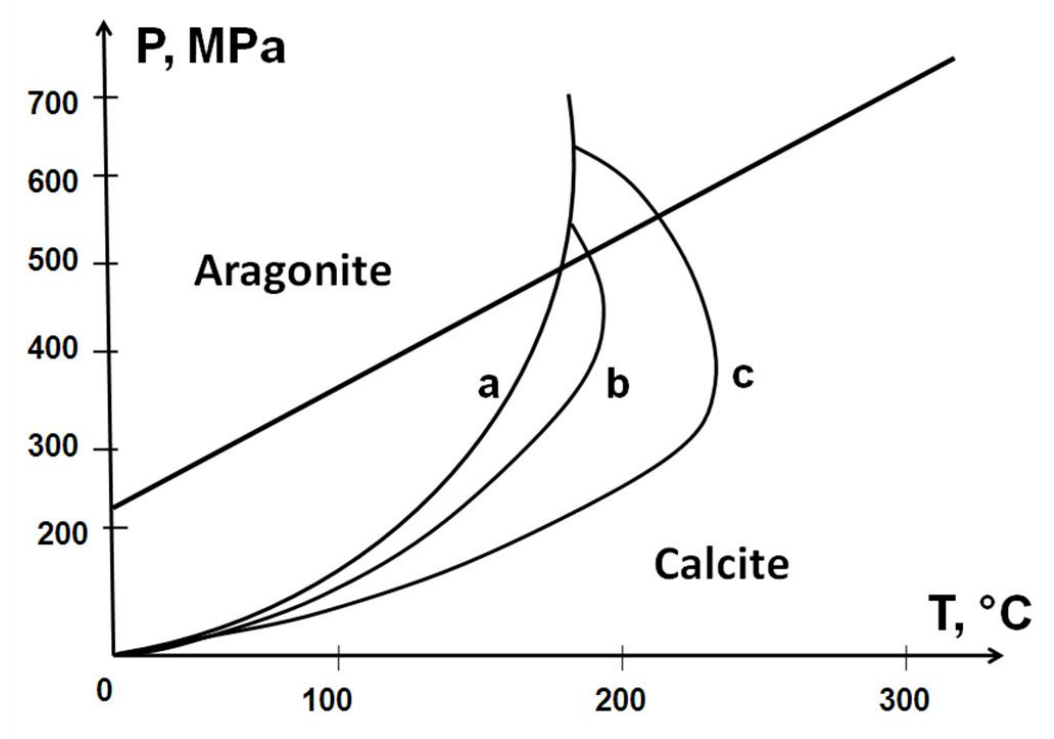


Fig. 8. Selected P-T trajectories for uplift paths of aragonite-bearing rocks from blueschist facies metamorphism. The aragonite/calcite phase boundary is shown by a bold line. Curves (a), (b) and (c) are possible cooling and uplift paths for Franciscan rock under different conditions (uplift rates 1-3 $\mathrm{mm} /$ year, initial depth $\sim 20-30 \mathrm{~km}$ ), according to ${ }^{[27]}$.

In the study of Liu with collaborators ${ }^{[28]}$, a series of Raman experiments on the phase transition of calcite at high pressure and high temperature were carried out using a hydrothermal diamond anvil cell. It was found that calcite I transformed into calcite II and calcite III at pressures of 1.62 and 2.12 GPa and room temperature. With increasing temperature, the phase transition of calcite III into aragonite occurred. Aragonite was retained upon slowly cooling of the system, indicating that the transition of calcite III into aragonite was irreversible. Kinetics of calcite-aragonite transformation to a first order approximation may be estimated from a time dependence of electrical bulk resistance ${ }^{\text {[29] }}$. For example, at $2.5 \mathrm{GPa}$ and $780{ }^{\circ} \mathrm{C}$ the characteristic transformation time is $\sim 7.5 \mathrm{~h}$, at $2 \mathrm{GPa}$ and 735 ${ }^{\circ} \mathrm{C} \sim 33 \mathrm{~h}$. So, aragonite as a high-pressure polymorph of calcite, could be stable for a long time at pressure starting $200 \mathrm{MPa}$ and low temperature.

\section{Conclusions}

Raman data of the Markovka (H4) meteorite provides a basis for new unexpected constraints for both main models of a H-chondrites parent asteroid. For the "onion-shell" model, size of the body, accepted for calculations, remains under question. So, aragonite as a high-pressure carbonate polymorph could be formed from calcite during a strong impact followed by quenching. With a mean density of chondrites as 3-4 g/ $\mathrm{cm}^{3}$, pressure of $200 \mathrm{MPa}$ at body with a radius $\sim 300 \mathrm{~km}$ is possible, according to (2). Theoretically, aragonite could be preserved in a parent body of this size until its destruction. But, current accretion models suppose a quite short time interval of ca. 1-2 Mio. years (since Ca-Al inclusions formation) and planetesimals with a preferential size of ca. 50-200 km in radius ${ }^{[30]}$. And, for this option, Markovka does not contain essential impact melt (see Fig. 1) and the structure of olivine in chondrules is typical for S0-S1 degree of the shock metamorphism.

The "metamorphosed-planetesimal" model is more likely, assuming that aragonite was deposited from a Mg-rich solution, like hydro-alteration by CM carbonaceous chondrites ${ }^{[24]}$. In this case, the question about the possible water source arises. If these were grains of water ice, then early migration of the Markovka" parent body to the "snow line" was necessary. So, Raman map on the Figure 4 reveal asteroid aqueous alteration by cementation of pores produced by the melting of tens of micrometersize particles of $\mathrm{H}_{2} \mathrm{O}$-rich ice. Also, presented Raman data concerning maghemite confirms this possibility: the presence of ice due to the latent heat of melting could significantly lower the overall temperature.

In the example of Markovka (H4), we can see as chondrite' meteorites store the keys on evolution processes at the early solar system. Raman spectroscopy provides additional unique possibilities for their study of chemical and mineralogical analysis.

\section{Acknowledgment}

The study was supported by the Russian Science Foundation (project no. 21-17-00120). We acknowledge the access to Raman laboratory of the DLR Institute of Planetary Research in Berlin. 


\section{References}

[1] J. T. Wasson, Meteorites: Their Record of Early Solar System History. Freeman \& Co., New York, 1985.

[2] G. R. Huss, A. E. Rubin, and J. N. Grossman, Thermal Metamorphism in Chondrites, In:

Meteorites and the Early Solar System II, Eds. D. S. Lauretta and H. Y. McSween Jr., University of Arizona Press, Space Science Series, 2006 (pp. 567-586).

[3] L. Pittarello, K. Baert, V. Debaille, P. Claeys, Meteoritics and Planetary Science. 2015; 50: 17181731 .

[4] L. Bonal, E. Quirico, L. Flandinet, G. Montagnac, Geochim. Cosmochim. Acta. 2016; 189: $312-$ 337.

[5] B. J. Saikia, G. Parthasarathy, R. R. Borah, R. Borthakur, A. J. D. Sarmah, J. Astrophysics \& Aerospace Technology 2017; 5: 100149.

[6] A. Wesełucha-Birczyńska, M. Zmudzka. J. Mol. Struct. 2008; 887: 253-261.

[7] D. Kaeter, M. A. Ziemann, U. Böttger, I. Weber, L. Hecht, S. A. Voropaev, A. V. Korochantsev,

A. V. Kocherov, Meteoritics and Planetary Sciences. 2018; 53: 416-432.

[8] R. N. Clayton, Annu. Rev. Earth Planet. Sci. 1993; 21: 115-149.

[9] P. Pellas and D. Storzer, Proc. Royal Soc. London. 1981; 374: 253-270.

[10] E. R. D. Scott and R. S. Rajan, Geochim. Cosmochim. Acta 1981; 45: 53-67.

[11] H. Y. McSween and A. D. Patchen, Meteoritics. 1989; 24, 219-226.

[12] M. Trieloff, E. K. Jesserberger, I. Herrwerth, J. Hopp, C. Fiernl, M. Gherlls, M. Bourot-Denise, P. Pellas, Nature. 2003; 422: 502-506.

[13] E. R. D. Scott, 66th Annual Meteoritical Society Meeting. 2003; Contribution \#5293.

[14] L. Landau, E. Lifshitz, Theoretical physics. v.7 Theory of elasticity 1987; M., Nauka, p. 245.

[15] S. A. Voropaev, A. V. Kocherov, C. A. Lorenz, A. V. Korochantsev, N. V. Dushenko, D. M.

Kuzina, I. I. Nugmanov, and Y. Jianguo, Doklady Physics. 2017; 62, 486-489.

[16] Meteoritic Bulletin. https://www.lpi.usra.edu/meteor/metbull.php?sea=Markovka\&sfor=names

[17] K. E. Kuebler, B. L. Jollif, A. Wang, L. A. Haskin. Geochim. Cosmochim. Acta. 2006; 70: 62016222.

[18] T. Mouri, M. Enami, J. Mineral. Petrol. Sci. 2008; 2, 100-104.

[19] A. Chopelas, American Mineralogist. 1991; 76, 1101-1109.

[20] J. J. Freeman, A. Wang, K. E. Kuebler, B. L. Jolliff, L. A. Haskin, Canadian Mineralogist. 2008; 46, 1477-1500.

[21] A. Wang, B. Jolliff, L. Haskin, K. Kuebler, K. Viskupic, American Mineralogist. 2001; 86, 790806.

[22] F. E. De Boer, P. W. Selwood, J. Am. Chem. Soc. 1954; 76, 3365-3367.

[23] D. L. A. de Faria, S. V. Silva, M. T. de Oliveira, J. Raman Spectrosc. 1997; 28, 873-878.

[24] M. Hanesch, Geophys. J. Int. 2009; 177, 941-948.

[25] M. R. Lee, P. Lindgren, M. R. Sofe, Geochim. Cosmochim. Acta. 2014; 144, 126-156.

[26] F. Rull, J. Martinez-Frias, A. Sansano, J. Medina, H. G. M. Edwards, J. Raman Spectrosc. 2004; 35, 497-503.

[27] M. Liu, R. A. Yund. Contrib. Mineral Petrol. 1993; 114, 465-478.

[28] C. Liu, H. Zheng, and D. Wang, High Pressure Research. 2017; 37, 545-557.

[29] N. Bagdassarov, A. Slutskii, Phase Transitions. 2003; 76, 1015-1028.

[30] E. Chiang, A. Youdin. Ann. Rev. Earth Planet. Sci. 2010; 38, 493-522. 